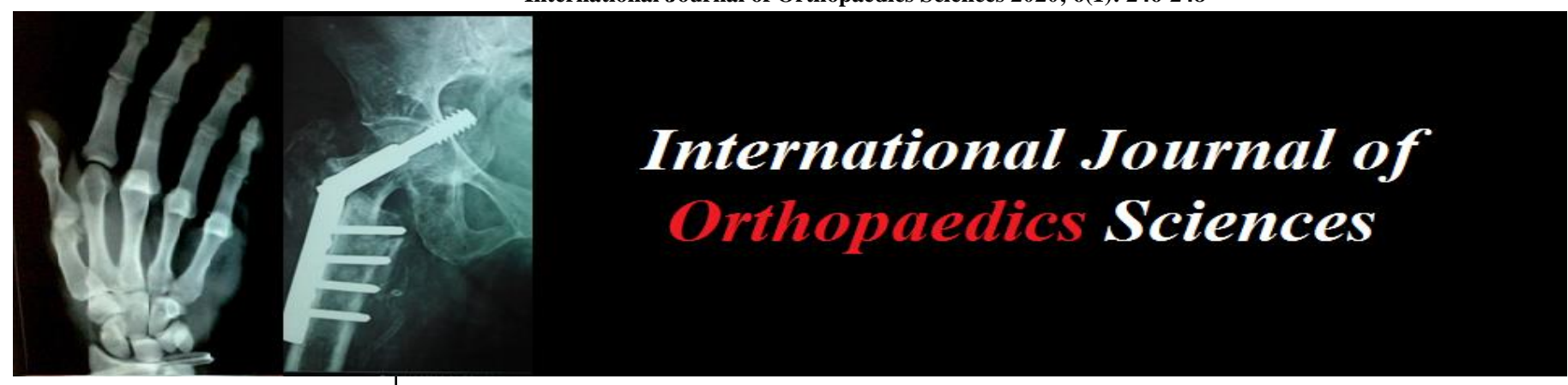

E-ISSN: 2395-1958

P-ISSN: 2706-6630

IJOS 2020; 6(1): 246-248

(C) 2020 IJOS

www.orthopaper.com

Received: 01-11-2019

Accepted: 05-12-2019

\section{Dr. Rahul Kumar Chandan} Specialist Medical Officer, Department of Orthopaedics, PMCH, Dhanbad, Jharkhand, India

Dr. VP Sinha

Associate Professor, Department of Orthopaedics, PMCH,

Dhanbad, Jharkhand, India
Corresponding Author: Dr. Rahul Kumar Chandan Specialist Medical Officer, Department of Orthopaedics, PMCH, Dhanbad, Jharkhand, India

\title{
Diagnosis and management of giant cell tumour of talus: A case report
}

\section{Dr. Rahul Kumar Chandan and Dr. VP Sinha}

DOI: $\underline{\text { https://doi.org/10.22271/ortho.2020.v6.i1e.1866 }}$

\section{Abstract}

Giant cell tumor (GCT) of bone involving small bones of hand and feet is a rare entity. But in foot and hand it is more aggressive and recurrence rate is high as compared to long bones. We report a rare case of GCT of talus that was managed on the lines of tuberculosis by an orthopaedic surgeon for six months. Core biopsy of the lesion revealed multinucleate giant cells on histopathological examination suggestive of GCT or aenurysmal bone cyst (ABC). Extended curettage and bone grafting was done. Histopathology of the curettage confirmed the lesion as GCT. The patient was followed for a period of 24 months and there was no local recurrence or lung metastasis. So it is concluded lytic lesion involving small bones of hand and feet can be a presentation of any disease ranging from infection to a tumor and GCT should always be kept as a differential. And these lesions should be routinely subjected to core or open biopsy to confirm the clinical diagnosis.

Keywords: Curettage, giant cell tumor, multinucleate giant cells, talus

\section{Introduction}

GCT of bone is a benign locally aggressive tumor which usually involves epiphyses of long tubular bones. Involvement of small bones of hand and feet is rare. ${ }^{[1,2,3]}$ Not many cases involving talus have been reported and as per literature only 14 cases of talar involvement have been reported until year $2012^{[4]}$.

\section{Case report}

Twenty two year old male patient presented to our institute with chief complaint of progressively increasing pain for last one and a half year and intermittent swelling for last six months of the right ankle. There was no history of trauma, fever, loss of appetite or similar involvement of any other joint. One year back patient had consulted a local orthopaedic surgeon for his complaints and was diagnosed to be suffering from tuberculosis of talus from the evidence of raised erythrocyte sedimentation rate (ESR) of 45 millimetres in first hour. Radiograph of right foot revealed a lytic lesion in head, neck and anterior part of body of talus, CT scan of foot had an impression of cystic, septate lesion involving head, neck and part of body of talus without involvement of the adjacent joints, Core biopsy of lesion was done under fluoroscopic control and histopathology of the same had presence of multinucleate giant cells.

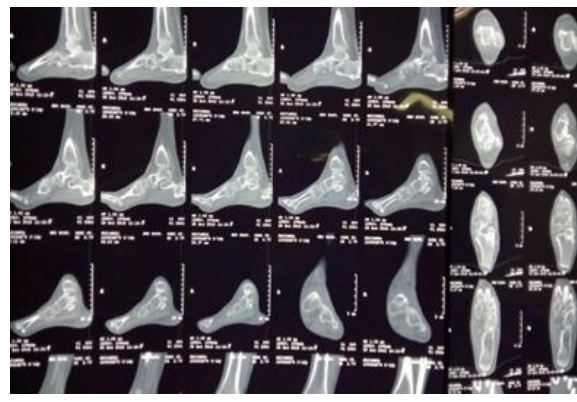

Ct Scan of Foot

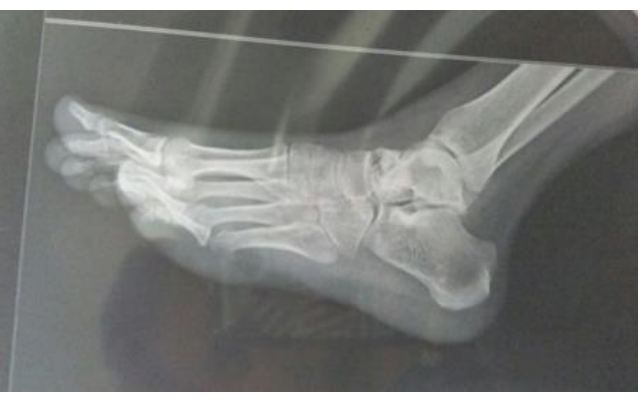

Pre - OP xray 
Differential diagnosis of aneurismal bone cyst (ABC) and GCT was made and was planned for extended curettage. Talus was approached by standard anterior approach. A window was created in the region of neck and adjacent head and body of talus. Lesion was curetted out thoroughly followed by removal of residual tumor from walls by a high speed burr. Alcohol was used as an adjuvant for extended curettage. The defect was filled with G-bone graft. Histopathology of the curetted material had features consistent with GCT. In the postoperative period patient was not allowed to bear weight for eight weeks followed by gradual increase in weight bearing in a protective plaster of Paris cast for six weeks. Patient was followed every three monthly in first year and then six monthly for next one year for local recurrence and pulmonary metastasis. At final follow up at 24 months there was no local recurrence with painless functional ankle and foot.

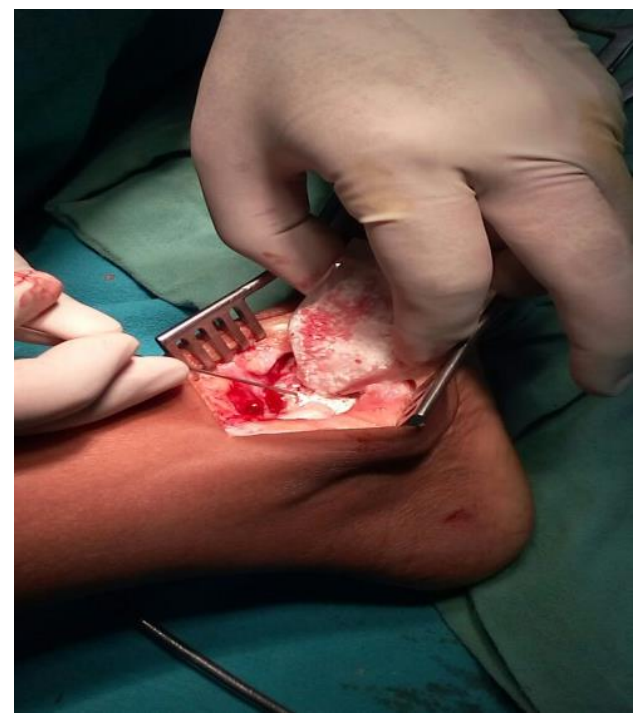

G-bone insertion

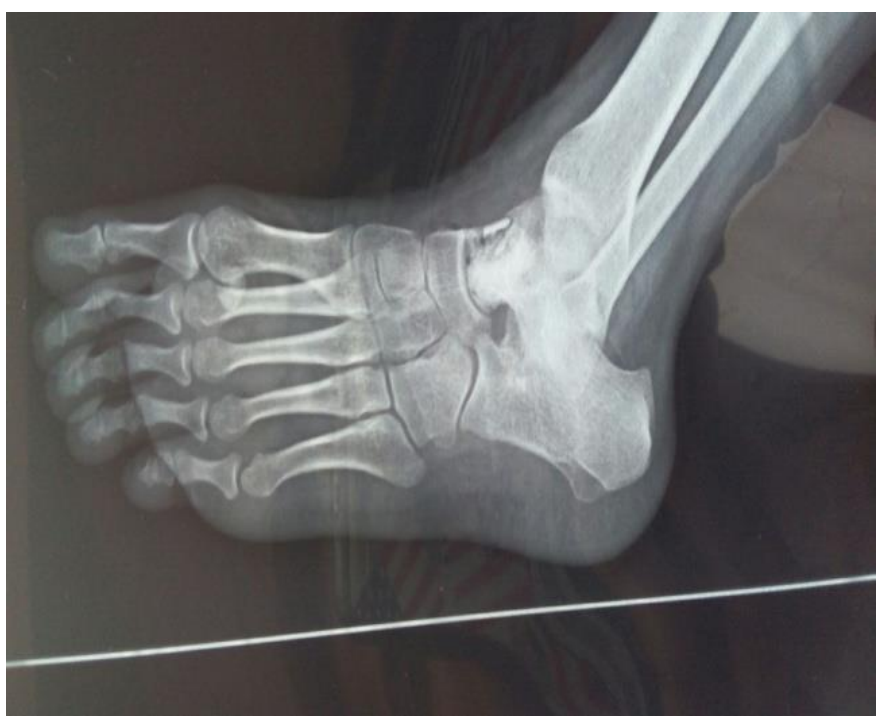

Post OP X - ray

\section{Discussion}

GCT of bone accounts for 4 to $5 \%$ of primary bone tumors. ${ }^{[5]}$ The most common site is around knee joint and distal radius. ${ }^{[5,6]}$ Involvement of small bones of hand and feet is rare. ${ }^{[3,6,7]}$ In different studies incidence in hands and feet range from 1.7 to $4 \%$ and 1.2 to less than $2 \%$ respectively. ${ }^{[1]}$ GCT of talus is uncommon and as per literature only 14 cases had been reported till 2012. ${ }^{[4,8]}$ Small bone GCT differs from that of long bones in being more aggressive, higher rate of recurrence, onset at younger age, and tends to be multicentric. $[3,9,10]$ Hence small bone GCTs need to diagnosed early and treatment should be aggressive. GCT of talus typically presents with pain and or swelling of the ankle joint with or without history of trivial trauma and can be easily misdiagnosed as ankle sprain. ${ }^{[1,11]}$ Radiographic picture of GCT of small bones can mimic variety of pathologies ranging from any type of osteomyelititis and benign tumors to an aggressive bone tumor, as had happened in our case which was being treated as tubercular osteomyelitis of talus by a local orthopaedic surgeon. ${ }^{[12]}$ Histopathology of GCT of bone shows an overlap with other giant cell rich lesions like ABC and giant cell reparative granuloma making diagnosis difficult. It is the presence of 'Dahlin's diagnostic areas' consisting of uniformly distributed giant cells in mononuclear round-oval stromal cell background which allows appropriate diagnosis of GCT. ${ }^{[1]}$ Management of GCT of small bone of hand and feet depends on the local extent of the tumor. ${ }^{[1,4,11]}$ Simple curettage with bone grafting for GCT of tarsal bones has a very high recurrence rate of $75 \%$ to $80 \%$ while as simple curettage without bone grafting has a recurrence rate of $50 \% .{ }^{[1,10]}$ In our case tumor was restricted to talus and was managed by extended curettage and bone defect filled with Gbone graft. Many surgeons use bone cement as a filling agent as it also serves as an adjuvant to kill the tumor cells but we preferred bone grafting as only paper like thin rim of subchondral bone was left after curettage of the lesion and bone cement might have induced degenerative changes in the overlying articular cartilage. ${ }^{[1]}$ There was also a concern that bone cement may leak through a small defect, which was created during curettage, into the subtalar joint thus accelerating degenerative osteoarthritis. Biscaglia $\mathrm{R}$ et al in their series had eight patients of GCT of small bones of hand and feet treated by extended curettage using phenol adjuvant without any recurrence ${ }^{[1]}$. Similarly in our case there were no signs of recurrence at 30 months follow up. Other treatment options depending on the extent of the disease are partial or total talectomy with arthodesis and amputation. Simple curettage with bone grafting has higher rate of recurrence so extended curettage with adjuvants like bone cement (methylmethacrylate), phenol, liquid nitrogen, cryotherapy is recommended if bone is salvageable ${ }^{[1,6,9,11]}$.

\section{Conclusion}

GCT of talus is a rare entity which can mimic clinically with ankle sprain, radiologically to variety of entities ranging from osteomyelitis and benign tumor to an aggressive tumor and histo-pathologically to $\mathrm{ABC}$ and giant cell reparative granuloma. Hence long standing symptoms of the ankle joint always need radiological evaluation and if lesion involves a tarsal bone diagnosis should be established by histopathology of core biopsy and if inconclusive open biopsy should be taken. Pathologist needs to differentiate GCT from other giant cell rich lesions like $\mathrm{ABC}$ and giant cell reparative granuloma by searching for 'Dhalins diagnostic areas', a characteristic feature of GCT. Treatment of GCT talus should be based on extent of the lesion and if salvageable extended curettage is the treatment of choice. Though use of methylmethacrylate as a filling agent as well as an adjuvant is a standard nowadays but should be avoided in small tarsal bones if there is thin papery subchondral bone left or there is a rent in articular 
cartilage during preceding curettage to prevent subsequent cement induced degeneration and osteoarthritis.

\section{References}

1. Biscaglia R, Bacchini P, Bertoni F. Giant cell tumours of the bones of the hand and foot. Cancer. 2000; 88:202232.

2. Dhillon MS, Singh B, Gill SS, Walker R, Nagi ON. Management of giant cell tumor of the tarsal bones: a report of nine cases and a review of the literature. Foot Ankle. 1993; 14(5):265272.

3. Dhillon MS, Prabhudev Prasad AP, Virk MS, Aggarwal S. Multicentric giant cell tumor involving the same foot: A case report and review of literature. Indian J Orthop. 2007; 41:154-7.

4. Murali SM, Moirangthem V, Mothilal SN. Giant cell tumor of talus - A rare presentation \& our management. Pb J Orthop. 2012; 13(1):89-92.

5. Riddle ND, Yamauchi H, Caracciolo JT, Cheong D, Khakpour N, Bui MN. Giant cell tumor of the anterior rib masquerading as a breast mass: a case report and review of current literature. Cases J. 2010; 3:51.

6. Bapat MR, Narlawar RS, Pimple MK, Bhosale PB. Giant cell tumour of talar body. J Postgrad Med. 2000; 46:110.

7. Campanacci M, Baldini N, Boriani S, Sudanese A. Giant cell tumor of bone. J Bone Joint Surg Am. 1987; 69:106114.

8. Kinley S, Wiseman F, Wertheimer SJ. Giant Cell Tumour of the talus with secondary aneurysmal bone cyst. J Foot Ankle Surg. 1993; 32:38-46.

9. Kumar JM, Gowda N. Giant Cell Tumor of Talus: A case report of late presentation with extensive involvement. Foot Ankle Online J. 2011; 4(1):1

10. Wold LE, Swee RG. Giant cell tumor of the small bones of the hand and feet. Semin Diagn Pathol. 1984; 1:173184.

11. Sharma S, Wani IH, G Nital, Mahajan N, Salaria AQ. Giant cell tumor of talus: a case report. Cases J. 2009; 2:74.

12. Ali N, Bhat A, Muzzafar K, Fatima A. Isolated cystic tuberculosis of medial cuneiform: a case eport. Int J Res Med Sci. 2013; 1:592-5. 